\title{
Supporting Decision Making Process with “Ideal” Software Agents - What Do Business Executives Want?
}

\begin{abstract}
According to H. Simon's (1977) decision making theory, intelligence is the first and most important phase in the decision making process. With the escalation of information resources available to business executives, it is becoming imperative to explore the potential and challenges of using agent-based systems to support the intelligence phase of decision-making. This research examines UK executives' perceptions of using agentbased support systems and the criteria for design and development of their "ideal" intelligent software agents. The study adopted an inductive approach using focus groups to generate a preliminary set of design criteria of "ideal" agents. It then followed a deductive approach using semi-structured interviews to validate and enhance the criteria. This qualitative research has generated unique insights into executives' perceptions of the design and use of agent-based support systems. The systemic content analysis of qualitative data led to the proposal and validation of design criteria at three levels. The findings revealed the most desirable criteria for agent based support systems from the end users' point view. The design criteria can be used not only to guide intelligent agent system design but also system evaluation.
\end{abstract}

Keywords: design criteria, business executives, intelligent software agents, decision support systems, decision making process.

\section{Introduction}

As the business environment becomes more volatile, unpredictable and competitive the appropriate handling of information and making sense of it has become a distinct core competence of business executives. The capability for managers to know their company, its competitors, and the business environment and make informed decisions, can significantly affect business competitiveness and success. There is an increasing complexity and dynamism of operational and strategic information in electronic and distributed environments. Executives are constantly seeking assistance for continuous, proactive and self-adaptive approaches to acquiring, synthesising and interpreting information for business intelligence with a view to determining a course of action. Executive Information Systems (EIS) originally emerged as computer-based tools to provide executives with easy access to strategic information and to support and enhance their information processing activities; however, EIS as a standard alone application have started to disappear since the mid-1990s. It is reported (Averweg and Roldán, 2007; Basu et al., 2000) that EIS in most organizations have moved on to 
Internet-based systems, and some of the key functions have merged with the latest enterprise systems, for example, the ERP and Business Intelligence (BI) systems that embed executive dashboards, scorecards to present / report synthesised information to senior management (Simons, 2008). Past studies on EIS have established a range of views and guidelines for developing systems for executives, but these guidelines largely failed to develop robust and intelligent systems to meet emerging challenges.

The emergence of the intelligent software agent, as a concept and a technology, has been put forwarded as one of the solutions for reducing information overload problems faced by contemporary business organisations (Belfourd \& Furner, 1997; Edmunds \& Morris, 2000) and supporting business executives' intelligence activity for decision making in the more integrated and distributed environment of the Internet. However, there has been strong criticism that "there is a truly dearth of such work in the literature that reports on real users' views on specific personal agents" ((Nwana \& Ndumu, 1999) p.136). Not much progress appears to have been made to address this criticism since. One of the factors contributing to the lack of interests in users' viewpoint in Information Systems (IS) is due to the factor that "IS are often developed and studied from an organisational viewpoint ... rather than how they support individual users, their characteristics, preferences and actions." (Iivari et al., 2010). Arnott and Pervan [2] pointed out that one of the fundamental issues that needs to be addressed by DSS researchers is a crisis of professional relevance. Many IS researchers also stress that both technical and human factors should be considered in the IS design and development process (e.g. Avison et al., 2001; Mumford, 2006; Kling, 2007). In examining the relationship between user participation and Decision Support Systems (DSS) outcomes, Lynch \& Gregor (2004) found out that much previous research focused on whether users were involved in development without the detailed consideration of the degree of their influence on system design features. Users, i.e. business executives, in this research context, should have their views considered and be able to influence agent design features. Therefore executives' desires and views on agent-based support should be investigated in order to design and develop agent-based support systems that will be accepted by and workable for them.

This research aims to explore the potentials of agent based systems for supporting the intelligence phase of decision making and contribute to a better understanding of users' expectations and requirements of designing and developing intelligent software agents from business executives' perspective. The research adopted a qualitative method from the system client perspective with an interpretative data analysis approach, therefore, the outcomes would motivate agent support system researchers to focus on issues of current importance and relevance to business executives (Arnott \& Pervan, 2005).

This paper first examines the theoretical underpinning for supporting executive intelligence activities, which involves information processing and sense making, and the need for designing agent based support systems 
that are capable of responding and adapting to executives' decision making needs. It also reviews the literature on software agents and its potential for supporting executives' intelligence activities. The research adopted a qualitative approach to achieve its aims by using an agent interface prototype as a tool to help executives to understand the agent concept. Opinions were generated through focus group discussions and personal face-to-face interviews. Based on a rigorous content analysis using qualitative software, Nvivo, a set of design criteria was generated from focus group findings and confirmed with interviews. The design criteria has three-levels, comprising a "usability-adaptability-autonomy" trichotomy for supporting executive intelligence activities. The emphasis of this agent system design model is an intelligent and executive-centred system which can be used not only to guide agent support system design, but also the evaluation of the intelligent support systems.

\section{Literature review}

\subsection{The decision making process}

Effective decision making is the most important part of a senior manager's job. However, it is also the most challenging task they face in their managerial responsibilities. A number of scholars have contributed to the field of understanding the nature and the process of decision making, One of the most notable is Simon's (1977) work on the "new science of management decisions".

Simon (1977) proposed a generic decision making process which follows intelligence-design-choice phases. In his theory, he states that decision makers spend a large fraction of their time surveying the organisational environment to identify new varieties that call for new actions in the "intelligence" phase. In the "design" phase they individually, or with their subordinates, design and develop possible courses of action for handling situations where a decision is needed. In the "choice" phase, they select from those available courses of actions to meet and solve an identified problem.

The intelligence phase entails scanning the environment, either intermittently or continuously (Turban \& Aronson, 1998). It is argued that the support for the "intelligence" phase is of particular importance and critical, because the intelligence phase is the first principal phase, which emphasises the search for variety, occasions, or conditions that call for decisions. In the intelligence phase, the environment is examined and problem areas, as well as opportunities, are identified. Besides the identification of problems or opportunities, the intelligence phase also involves classification of the opportunity or problem from the business environment. The intelligence phase, however, has often been neglected in DSS design and development. 


\subsection{Executives' intelligence activities}

Business executives are senior managers who are responsible for strategic decision making in an organisation. Therefore, their decisions are critical and have profound human, financial and organisational impact. With the increasing availability of electronically distributed information, managers suffer from information overload, especially an over abundance of irrelevant information (Maes, 1994; Shapira et al., 1999; Eppler \& Mengis, 2004). As a result, senior executives are facing increasing complexity, diversity and uncertainty in processing information for making decisions. Senior executives simply cannot relate simultaneously to all of the information available to them. They have to select and then make sense of what is selected. Ackoff (1967) foresaw this dilemma with the introduction of management information systems (MIS). He strongly believed that the emphasis of an executive support system should shift from supplying relevant information to eliminating irrelevant information. He argues, "Unless the information overload to which managers are subjected is reduced, any additional information made available by an management information systems cannot be expected to be used effectively" (Ackoff, 1967, p. 148).

Simon's (1977) intelligence phase requires executives to carry out a number of core activities in order to identify opportunities, problems and needs, which call for decisions. The key activities carried out in the intelligence phase are information acquisition through environment scanning, information synthesis and sense making. These core activities are defined as "Intelligence Activities" in this paper. Support for executive intelligence activities is essential for them to better cope with the increasingly dynamic and unpredictable environment.

In order for executives to understand their internal and external business environment and to attend to signals and messages generated from those environments, they need a system that is capable of providing a broad range of relevant information. Although companies have little control over external events, information acquisition activity can reduce remoteness and increase the predictability of future possibilities. Information synthesis in executive intelligence activities involves information filtering and refining. Information synthesis acts as a "variety reducer" by screening out irrelevant information and refining information through relevance feedback for their relevancy. Finally, sense making is pertinent to executive intelligence activities. Synthesised information is further processed to resolve the equivocality of information and to give meaning and understanding. Explanations are key functions in sense making activity, in which explanations help provide adequate justification on information such as the meaning of data, the justification for a particular piece of information and the reasons for advising a particular course of action. Identified opportunities and problems in the intelligence phase trigger the phase two and three activities. 


\subsection{Intelligent agents}

Intelligent agents, or software agents, are "software entities that carry out some set of operations on behalf of a user or another program with some degree of independence or autonomy, and in doing so, employ some knowledge or representation of the user's goals or desires" (Maes, 1994, p.31). While not necessarily as intelligent as a human agent, software agents can learn from interaction with the user, and proactively anticipate the user's needs (http://www.media.mit.edu/research).

In artificial intelligence research, agent-based systems technology has been hailed as a new paradigm for conceptualizing, designing, and implementing software systems

(http://www.cs.cmu.edu/ softagents/multi.html2009). The potential contributions of intelligent agents to DSS have been described as enormous in the past and re-emphasised by many researchers recently (Gao \& Xu, 2009). It is believed that intelligent agents' properties can facilitate active decision making, so they have appeared in an increasing number of DSS applications (Gao \& Xu, 2009). Many attempts have been made to develop intelligent agent-based system to support intelligence activities. Examples include an agent-based environmental health impact decision support systems (sokolova???); an intelligent agent informediary for web financial information to support decision making (Yang \& Chung, 2004); the agent-based negotiation process for B2C e-commerce (Huang???); design and development of agent-based procurement system to enhance business intelligence (Lee et al., 2009), and conceptual modelling and development of an agent-based DSS for anti-money laundering (Gao \& Xu, 2009). However, despite the advances in technologies in many areas, most of the intelligent agent systems, as reported, are either conceptual models, prototypes, or under development.

\section{Research method}

As the focus of information systems research shifts from technological to managerial and organizational issues, qualitative research methods become increasingly useful (Myers, 1997). Information systems researchers argued over a decade ago for the need to use qualitative approaches to supplement the widely used quantitative approaches (Lacity \& Janson, 1994), but DSS research was criticised as "overwhelmingly positivist, and more dominated by positivism than IS research in general" (Arnott \& Pervan, 2005, p.67). There is a call for conducting qualitative research and using an interpretive approach in DSS investigations (Myers, 1997; Arnott \& Pervan, 2005). Therefore, this study adopted a qualitative approach in an attempt to have greater open-mindness and a more in-depth understanding of designing and using agent system to meet executives' challenges and requirements in supporting their intelligence activities in decision making. To identify what executives want from an intelligent agent-based system, the research was carried out in the following sequence: 
1. Literature review to understand the theoretical background, technology development and research rationale.

2. Design of an agent system interface prototype as a visualisation tool to help executives understand the concept and technology.

3. Three focus group discussions to stimulate and collect executives thoughts and views on challenges, needs, and criteria of their ideal agents

4. focus group analysis to generate themes and initial design criteria model

5. Twenty-five face-to-face interviews with senior executives to further strengthen and validate executive criteria for agent system design

6. Refinement of the final design-criteria from an executive's perspective.

In order to facilitate executives' understanding of the concepts of software agents, a web-based visualisation prototype was designed to demonstrate the main attributes of an agent (see a sample user interface in figure 1.). In order to explore and communicate propositions about the interface design and its context prototypes can range from sketches to different kind of models at various levels, e.g. "looks like," "behaves like," "works like",(Buchenau \& Suri, 2000). The visualisation prototype served as a demonstration tool to enhance executives' understanding, rather than as a tool for technological implementation.

(Figure 1. Sample user interface of agent supported interpretation and learning is about here).

\subsection{Focus groups}

The purposes of the focus group were to understand the challenges and needs in supporting executive intelligence activities, and more importantly stimulate their thoughts on what support they would like the agent to offer. The main questions asked for the focus groups were:

1. What are the challenges of today's executive intelligence activities in their decision making process?

2. If software agents can play a part, what would be your ideal software agent; what are your desires or expectations for software agents to support your intelligence activity?

Three focus group discussions were conducted with a total of 31 business executives who were attending part time executive MBA and CMI (Charted Management Institute) courses. Details of the focus group participants are given in Table 1.

(Table 1. Participants profile of focus groups is about here.) 
Participants were from different industry backgrounds, most of them were at strategic and managerial levels.

Each session began with a brief statement on the rationale and objectives, the confidentiality and ground rules for the discussion and the demonstration of the agent visualisation model. All focus group sessions took about an hour to complete. The discussions were tape recorded for data analysis and field notes taken.

The method of thematic qualitative analysis (TQA) (Mason, 2002) was used to elicit related themes in the text data collected during the discussion. This was followed by a categorisation process that identifies relationships between the themes and the meaning from the text in the transcripts. The focus group discussion were transcribed and compared with the field notes taken by a colleague who served as an observer to assure the validity of the focus group study. Reliability in the form of inter-rater reliability analysis (Morse, 1997) was achieved through the use of two research colleagues as separate interpreters with a view to assessing the inter-subjective agreement among interpreters.

\subsection{Semi-structured interviews}

Semi-structured interviews were used to further enhance and validate the outcomes generated through focus group discussions and gain deeper insight into the thoughts and rationale for such outcomes. Open-ended questions provided the executive with the sense of control, as well as providing the possibility for executives to elucidate their answers or introduce further relevant information that may not have been discovered in the focus groups.

The sample was drawn from the FAME (Financial Analysis Made Easy) online database. Over a hundred phone calls were made to randomly selected senior executives and twenty-five interviews were successfully completed. The profile of the 25 participants is presented in Table 2.

\section{(Table 2 Interview participant information is about here).}

Most of the participants worked in medium and large organizations in the London area. Interviews lasted between 45 and 75 minutes and were conducted in the workplace of the interviewee. Interview contents were digitally recorded and transcribed verbatim for analysis. Due to the high volume of raw data obtained from the interviews the qualitative analysis software NVivo was employed to analyse the data. The categorisation of meaning approach, which is similar to the thematic qualitative analysis (TQA) was adopted for the semistructured interview analysis. All transcripts were coded into predetermined categories from the focus group study, as well as into newly emerging categories for analysis. For a more detailed interpretive conceptual analysis, meanings were sought from the quotes to identify consensus, dilemmas, and contradictions through 
reading and re-reading of transcripts (Nicolson \& Anderson, 2003). Selected quotes are provided as to illustrate the meaning within the right contexts.

\section{Generation of initial design criteria using focus groups}

\subsection{Preliminary findings from focus groups}

Through the initial exploration of the focus group study, the identification of executives' perceptions of agentbased systems supporting intelligence activities helps determine executives' criteria for ideal software agents. As described in the previous section, an inductive analysis procedure using thematic qualitative analysis (TQA) (Mason, 2002) was adopted to identify themes that emerged from raw data (text) from focus groups. First order themes that related to an ideal agent system are identified as: "ease of use", "personalisation", “controllability", "coaching", "learning”, "contextual support”, "semantic support", "spontaneity” and "proactivity". Three second order themes based on the first order themes were categorised as: usability, adaptability, and autonomy. The generation of the second order themes were based on both the context of the empirical data and the relevant IS literature on system design. Themes with examples of original quotations and related categorisations are organised into tree-structures, as illustrated in Table 3.

(Table 3. Thematic analysis of focus group data with sample supporting evidence is about here.)

\subsubsection{Usability}

Usability refers to the extent to which a system can be used by its users to achieve their goals with effectiveness, efficiency and satisfaction in a specified context of use (ISO 9241-11, Guidance on Usability (1998)). It is argued that "difficult to use software wastes the user's time, causes worry and frustration, and discourages further use of the software." (Bevan \& Macleod, 1994). Therefore, it is no surprise that usability related attributes which include personalisation, controllability, and ease of use, were perceived by particpants as a most important criterion for designing an agent-based system.

Findings suggest that the system must be user-centred in its assistance. This means that the system understands the relevant characteristics of end-users which is an important task of usability design (Bevan \& Azuma, 1997). Due to the nature of manager's roles and tasks, the system must be of ease of use. One participant compared the usability with how a human personal assistant would be able to assist and pointed out that "A personal assistant in a human form would know your personality, would have learned what to put forward and what not to put forward. I am not sure the IT software has the ability to take that information" (FG2). The agent should provide information in "a simple form but not in a complex form" (FG2) 
Usability requires personalisation in agent based systems (Kaasinen, 1999), in which information is processed according to the user's information processing behaviour and interests. The information provision is in relation to the context of the organisation and the specific requirements of the user. Participants argued that "The big mistake made is [that] the software developer drives what the rules are (not senior executives) (FG1). Executives wanted to have "rules around the context of the organisation of what you want to search, how you want to search, how you use it, and it almost needs to be tailored into the context of the organisation." [FG1]

According to the participants, it is important that the users can control the system for performance improvements. For example, users should be able to decide and control the amount, types and sources of information they want. Executive should be able to "define what he wants and how much control of information he will get." (FG3)

\subsubsection{Adaptability}

Adaptability refers to the system's capability "being able to learn a user's preferences and habits over time and adapt to the changing needs of the user" (Nwana \& Ndumu, 1999, P. 134) and is one of the desirable features of personal agent (Nwana \& Ndumu, 1999). Responding to the changes in their environment is one of the software agent attributes (Wooldridge \& Jennings, 1995). According to the participants, four attributes were related the adaptability design which include coaching, contextual support, learning, and semantic support. These attributes help to increase the level of relevance and contextualisation of information, with the appropriate semantic and contextual support. According to executives, an agent should be able to adapt to changing situation and individual executive's information processing behaviour through learning and coaching. Hence, the setting up of a user's profile must be specific to individual user's needs and industry sectors. It is important for the system to learn within itself (learning) or through user feedback (coaching). One manager suggests that the system “... must have a sort of flexibility within itself to retain as well as to develop." (FG1)

The key to ensure the adaptability is that the "agent knows very clearly what the executive is looking for and what structure or format he or she would like to have" (FG1). Most participants suggested that the great efforts are needed in order to coach the agent and to enhance its learning capability. A manager in FG1 stated "setting up the agent is where the work would be".

Participants also perceived the need for contextual support and semantic support as many were frustrated of the incapability of their information systems to retrieve information in the right context and right meaning. Participants argued that software agents should " actually tell you the context, justification of where the 
information are coming from..." (FG3) and "need to be knowledge-based in order to process and understand the level of importance ... the way to improve is to understand the natural language." (FG3).

\subsubsection{Autonomy}

Autonomy refers to the principle that agents can operate on their own without the need for human guidance, even though guidance would sometimes be invaluable (Nwana, 1996). The business environment continually creates signals and messages that demand executives' attention (Auster \& Choo, 1994; Kumar \& Palvia, 2001). Being autonomous is the key properties of a software agent (Wooldridge \& Jennings, 1995; Jennings et $a l ., 1998)$. Focus group results suggested that criteria for autonomy comprises two key attributes: spontaneity and proactivity. According to the participants, these are useful attributes of agents' support. The spontaneity attribute is perceived as the ability to perform the tasks spontaneously and autonomously. For example, they “...keep you updated with information from external business environment that is spontaneous.” (FG3), or

“... you set up to run overnight, or whatever, and when I come in the morning, there will be something to look at ..." (FG2).

According to the focus group participants, agents should be proactive. They should have the ability to make initiative in taking actions or bringing information into user's attention. For example, one participant suggested "If you are sure and you know who your competitor is, I suppose what you can do is to tag into their information bases, and just keep checking and when some information changes, it pops up to you. (FG2). You set them right and run them in the background. ... I mean as information is changing, it would pick it up and bring it to you." (FG2).

In addition to the design criteria, participants expressed their views on the general role of the software agent. Executives would treat an intelligent agent as a completely complimentary (FG2) tool that supports executive intelligence activity rather than in any way to "replace"(FG2) the executives. The main reason explained by the participants was the intuitive nature of many management decisions which requires human judgement. "One concern [about agents] is decision making must be based on rules. You have a set of rules, and so and so, all depends on the credibility of the rules you set up. Secondly, I think that a lot of decision making is intuitive" (FG2). Executives argued that they "make a decision from some instincts...that software doesn't have this intelligent instinct." (FG2).

\section{Design criteria validation using interviews}

Preliminary findings from focus groups suggested that central to developing ideal software agents from the executives' perspective is usability, adaptability and autonomy. Therefore, the focus of agent design should 
provide an agent-based information support environment in which executives can further adapt, control, coach and react according to their particular needs. The initial design criteria for ideal agents were further explored and validated using 25 face to face interviews as described in section 3.2. As in the focus group discussions, the visualisation prototype was used to demonstrate the main attributes of an agent and facilitate executive's understanding of the concepts of software agents. The main questions used in focus groups were repeated to the individual executives, but more specific questions regarding the three design criteria generated in focus groups were asked in the interview. For example, the interviewees were asked that "imaging you have software agents to support your intelligence activities, such as information acquisition, filtering, synthesising and interpretation, what would be your criteria? How would your criteria differ from those suggested by the focus groups?"

Discussion of the interview analysis together with selected direct quotations is presented in the following sections. Table 4 shows the percentage of different attributes identified by respondents for the three design criteria based on the interview data. The results show that usability (92\%) is considered the most critical, followed by adaptability ( $84 \%)$ and autonomy (64\%). Figure 2 depicts the final, validated, executives design criteria for ideal software agents.

(Table 4. A summary of interview data analysis about here.)

(Figure 2. Executives design criteria for ideal software agents about here.)

\subsection{Usability}

From the focus group study, three attributes contributing to usability emerged; ease of use, personalisation and controllability. These attributes served as the initial themes for interview data analysis. As shown in table 4, the findings, however, suggested that manageability was another important attribute which was related to the usability design and therefore was added to the final validated design criteria as shown in table 4 .

Figure 3 provides an example model of content analysis using Nvivo to illustrate the contributions from different participants. 23 out of 25 participants mentioned issues related to usability. The relationship between attributes can be seen to a certain extent by examining the frequency of different related attributes or issues raised by the same participant. Many intercepts can be seen in this model. The model shows that virtually all attributes are associated with one another. The strong interrelatedness of attributes suggests that participants are able to communicate the need for usability design with shared understanding and insights.

(Figure 3. An example of data analysis in confirming usability criteria using Nvivo about here.) 


\subsubsection{Personalisation}

According to participants, the main objective of personalisation is to produce information of users' interests. The problem with current system "is that it is not personalised, it is actually generic system that serves within the company" (Eve). So, participants stressed that "Absolutely, it should be customisable.", “as little generic as possible" (Larry) and "Very much depend on individuals" (Ford).

The concept of 'personal assistant' is well understood by senior executives. Participants saw the potential of having the software agents to act as their 'personal assistant' in their information searching and processing. "The whole point of this kind of intelligent agent that you are talking about is my personal assistant. It delivers me the most meaningful information and cuts out all the irrelevant one." (Larry). The role of an agent-based personal assistant must depend on individual executives, providing a personal service to users in accordance to their preferences, interests and needs. This includes the type of assistance an executive wants and how the executive wants to be assisted in different contexts. "It's a personal assistant, so it should have personal way to enable how the system should operate for you." (Ford). "it shouldn't become a barrier to information flowing to me." (Oscar).

\subsubsection{Controllability}

System developers are unlikely to know the specific information requests of executives because information requirements change over time and over different issues. Many participants stressed the need of having control over their specific information requirements and user profile (see the evidence in Appendix 1). Findings suggest that the more control over the system, the more likely executives are going to use the system. "if you could specify, that could be useful information that feeds into the system for my decision making." (Chris).

Controllability creates the flexibility of information acquisition and processing. Executives are allowed to give instructions to the system and can change and redesign their information domain and information profiles. For example, "It's not just a word search but the whole series of instructions that you can give, and perform the searches, takes out the rubbish, and present it to you for the course of action." (John). "A lot of systems today allow that [customisation] but they do not allow certain major definition change. ... one final thing would be system flexibility which allows users to change...." (Robert). "It needs to be easy to establish" and "allow people to change (Tim) 


\subsubsection{Manageability}

Manageability is the ability to cut down and break apart information to the appropriate level and amount for efficient processing. Most participants recognised the problem of information overload. Managers are constantly bombarded with information more than they can possibly assimilate (Edmunds \& Morris, 2000). Participants emphasised the need to reduce information provided to them by an agent to a digestible, manageable and appropriate amount at appropriate interval. The system should not only provide "relevant information, but with probably a digestible amount of relevant information." (William). "We don't want too much. It has to deliver an appropriate amount of information at appropriate interval." (Tim). "As the volume of information is exploded on the internet, ... we need to reduce to something manageable." (Peter). We "want to be able to drill down" and "to cut down to the bare minimum information I have to process." (William). The agent should provide "one set of information that allows a human to digest, because every brain has different size with different ability of processing power." (Robert).

It was also found that manageability is strongly linked to the decision making process. To make quick decision, executives need only few key indices of information that is readily processed and available. Ideally, the agent should not present too many decision points in one set of information. "If you want to make decisions very quickly, ... you want minimum amount of information, readily processed, so that you can click on." (John). "you need only a few key indices for decision making which means those information must be always readily available ...Information should be presented in very simplified form. Lots of time people present too many decision points in one set of information. (Robert)

Manageability is associated with the quality of information. According to the participants "...a dozen key drivers of business is manageable, anything more than that ends up lower quality. (Chris); "you don't want to be crowded with more than a certain numbers of handfuls of information." (Robert)

\subsubsection{Ease of Use}

Executives are impatient users due to daily time constraints, thus, unlikely to spend much time in using computer based systems. Several participants raised the need of having a simple and user-friendly interface because it "makes the whole interaction with the site much easier. Usually, the more easier the more you'd like to use it." (Ford). "You need to make this [agent system] simple, and more user-friendly" (Victor)

Senior executives are more acceptant to a system that leads them quickly to the information they want with minimum steps. Any complicated procedures are likely to hinder them from using the agent system. For example, " you just want to click, click, and click, and yes, that's what I want. Anything more than 4 levels 
will switch people off. So anything you design, maximum is 4 levels." (Ford). The system designers need "to keep things simple even it [the system] has advanced technology behind it." (Peter)

Executives prefer an user interface that is not "too busy and congested", yet "focus on key issues" (Smith). The key factor of the user interface is to increase the speed of information processing of executives. "Easy reading, that's crucial." (Smith)

\subsection{Adaptability}

Focus groups findings identified that four attributes are related to adaptability which are learning, coaching, contextual support and semantic support. These attributes were confirmed by interview findings (see table 4). Coaching is perceived more important than learning, in which executives were more willing to provide user feedback to the system than having the system learn about their behaviour in the background (see 5.2.1 below). Contextual support is perceived more important than semantic support. In addition to this, executives prefer to use natural language to acquire information, rather than identifying appropriate keywords for information searching.

\subsubsection{Coaching}

Coaching is considered the most important attribute in adaptability design. Participants expressed their desires of having the ability to coach the system by giving feedback, monitoring and revising the information processing process. "You have to give feedback to the system to increase the relevance of information." (Ken). The agent should have "the ability to keep track and revising and improving the filtering." (Eve)

Participants perceived coaching as an interactive process of assessing information received. "The current system is not interactive" (John). User should be able to tell the agent that " 'that's not what I want', or 'that's not what I asked for'." (John). "The other thing to help refine the system is that it can come back to me and say 'Did you get what you wanted?" (Ford). "If filtering and refining were interactive and intelligent, we can use the feedback to improve refinement." (Peter)

According to the participants, the coaching mechanism has to be very simple and straightforward, Clearly, senior managers are unlikely to commit to a complex mechanism. "...the feedback mechanism has to be as simple and straightforward as possible.” (Nelson). “... if you put in a request, may be 10 percent of information is really relevant, then you can tick a box just on the relevant one to say this is relevant." (Peter)

However, one participant expressed that "providing feedback would be useful if only you are not convinced that the system can give you what you want." (David). This implies that the coaching process will possibly 
and eventually become easier and less demanding as the user's confidence towards the system capability increases.

\subsubsection{Learning}

Learning is the capability of the system to improve itself by observing executives' information processing behaviours and information preferences without the feedback from the user. The learning mechanism requires time to learn about an individual executive through history, observation and imitation. Over time, the system builds the executive profile and eventually become more intuitive.

Participants recognised that the learning mechanism has to be intuitive and independent. Executives expected that "the agent was able, for a short while, spot the trend of information I am picking up. So, it could almost predict what I was going to look for on a daily or hourly basis. (John). The agent "is capable of learning about you, and after what you after, and tailoring its response to that.” (Tim). “...in an ideal world, the system would be intuitive. ...over time, it would know exactly what sort of information you are after." (Tim). The agent should be able to learn "what my requirements are and what really trigger my interests." and "it becomes intuitive." (Oscar)

The agent "will actually build its own understanding of what it has to do, through looking at what you actually do.” (Eve). “... When you put certain words down, it knows what it means because it learns from you a number of times before." (John). "Yes, mimicking the behaviour is a good way of learning” (William)

\subsubsection{Contextual Support}

Contextual support refers to the capability to provide information in the right context for the right user. Many participants raised the need for system to retrieve information in the right context, rather than information that just match the search keywords. For example, one senior executive stated that "our old information services had "Lloyds" included in it, so any article that had the word "Lloyds" in it would be automatically put forward. Now that meant that anything that has Lloyds Bank mentioned would also come through, also it meant at that time there were a lot of scandals going around "Lloyds" name whether it would be a story that is completely unrelated to insurance or just a little footnote with the "Lloyds" name." . Clearly, what executives want is a more advanced search and define feature that will acquire information that matches the context.

“...The current systems do not allow you to do that [contextual support], ...so [what we need] is the sophistication of defining exactly what you are looking for and then getting the system to deliver it in the right context." (David). Executives need "a more refined article selection process because if you have keywords, 
there is always the danger that the story itself is not about that keyword, it is just a word that gets mentioned." (Eve).

According to some participants, the context of information can possibly be improved by knowing more about the associative events of information or information background. For example, executives found that by knowing the information sources will help them to justify the quality of information better. "I probably would like to see the context that the piece of information is being taken from, so that I can judge whether I agree whether it is fairly presented or not." (Eve)

Contextual support can also be improved by knowing the history of information, for instance, how the word or information has been processed and used before, and how executive made sense of that information. It's about "the ability to put a word in the context.” (Ian). “...otherwise you will make the wrong decision.” (Robert)

\subsubsection{Semantic Support}

Semantic support refers to the systems' capability to assign meaning to the information with the availability of an ontology. Semantic support was not perceived as important as contextual support as participants recognised the challenges involved in providing semantic content. "We use terminology we know, ...one word in one language means one thing and another language means another thing. ...Let say, what 'passenger' means? In my context, consumer means airline passengers." (John). The agent should avoid "misinterpreting” (Ford). The semantic of information can possibly be improved by knowing more about the associative meanings. "Being presented with information is one thing, understanding what it means, is another." (Adam)

Some participants also perceived the need for natural language processing, in which the system is capable of categorising natural language texts into predefined content categories. The system thus knows what the user means. "The ability to define the natural language, what it is and what I want the system to do for me is very useful." (Ken). An ideal agent can be “...built in such a manner that it is speaking your language and knew exactly what you wanted" (Victor)

\subsection{Autonomy}

Focus group analysis identified two attributes contributing to autonomy: spontaneity and proactivity. The interview findings provide greater insights and confirm the two attributes. As shown in table 4

\subsubsection{Spontaneity}

Spontaneity is the capability to make spontaneous reactions without users' intervention. For example, executives would allow the agents to "process information continuously in the background", identifying 
information that might be of interest to the executive and bringing to the executive's attention on what is important. For example, "the search function on the browser is doing automatically, ...scanning and searching without input probably. (John). One executive imaged that "I could come in to the office each day, and I could, if I choose, turn on the tool and I say, 'Today, I am particularly interested in finding about motor insurance', and I put some filters in and it goes away. And after a time, I might go back let's say two hours later and see what it discovers." (Larry).

Executives often have time constraints due to the nature and the significance of their roles. It is unlikely that they are able to spend long hours processing and making sense of information, therefore, "continuous and autonomous is a good idea." (Tim). "The agents identify everything that could be critical in moving your business forward. ... so you can know things very early in the cycle" (William). "Clearly, an agent that alerts the significant changes of information, particularly information that is new, and recognise which information that has been used or which information is regularly used and then it somehow remember that and update that" (Larry). "If the system could respond to the change, yes, it will be very useful." (Chris). What executives "want is one set of criteria that is always there in the background, like keep an eye on what this company is doing, or report all news on this particular type of business." (Eve).

Some basic spontaneous functions were perceived as useful by executives, such as summarisation, categorisation and ranking. Executives would like to have "... some sort of summary to allow a quick scan on information (Oscar)"; and "...producing effective summary that is time saving (David)" and removes redundancy of information. "I suppose summarising, I mean eliminating duplication, you've got five different articles all telling you the same thing (William)".

Categorisation function can draw information from multiple sources into one place which is "...the ability to pick multiple sources about the same issue (Eve)" and provide indication of the relevance and usefulness of information, i.e. "differentiate between news that is urgent and information that you know" (Oscar). It can also increase the value of information, as explained by one executive that "as far as you know, every document could be important. I do not know how the system can get around it if the information just coming up without the classification. If the source of data can classify 1 is critical, 2 is important, 3 is not important, not mission critical something like that (Chris)".

Ranking functions enable executives to prioritise their information search and process, which provides "some ability to prioritise ... if you're not going to read anything else" (Adam)"; and helps executives to save time for other managerial activities, as explained by executives that "What would be useful for me is prioritisation 
... will save a lot of time, effort and energy (Ford)", "prioritise the information, ...that would save my time (Peter)".

\subsubsection{Proactivity}

Proactivity is the capability to act in anticipation of future goals so that its owner's objectives are met (Wooldridge \& Jennings, 1995). For example, participants expressed their needs for proactivity as ability to automatically exhibit actions that are beneficial to them, such as processing information in responding to their goals, making recommendations for action, distributing alert to relevant users, etc.

According to a number of executives, "...the recommendation feature might be useful (Tim)", "I'd say providing recommendation on the related articles (Smith)", and “...the agent is going to prompt me with additional information that I might find useful... (Adam)". Ideally, the proactive software agents are not only providing services in information processing, but working side by side with executives as a personal assistant. One participant expected that “...the agent is going to prompt me with additional information that I might find useful, ... an agent which is actually working with you, not only giving you information but also telling you what the relevance of the information is and how you might use that.” (Adam). It was predicted that “...eventually the system will become an assistant to figure out options for you.” (Yann). “...for example if you'd ask very specifically about the UK, but they may also say 'Well, you know there's an interesting article in relation to another European country ... ", (Smith)

It is important that the trigger information "should be readily available but should be available with an impact ... really hit the manager in the head like a bang on the head (Robert)". Although trigger information from an alert function was perceived as useful, executives are unlikely to want to be triggered too frequently. One executive emphasised that, "I wouldn't want something flashing out on my screen every five minutes to say that the information is there and I wouldn't want to actually go looking for it myself. I think it would be something if you would notify on a minimal daily basis, maybe twice daily to see whether the system had updated” (Mark). This implies a rather semi-intelligence of reactivity is needed in an agent-based system. “... a user should trigger and also be triggered by the information system” (Robert).

\section{Discussion}

It is argued by Mackrell et al. (2009) that users should be able to influence the DSS design process. Therefore, the design criteria of intelligent agent-based support systems should consider executives' perceptions in order to develop a system that is useful for them. Having analysed, interpreted and mapped out the rich texts collected from focus groups and interviews in the last section, this section discusses key research findings. 
The main outcome of the research is the proposal of a set of design criteria to guide design and development of the intelligent software agents from the business executives' perspective.

The usability-adaptability-autonomy design criteria as shown in figure 2 is a combination of insights from what the business executives want from ideal software agents and the development of the IS literature. The design model represents a hierarchical level of users' desires of an ideal software agent and the level of the system's intelligence.

\subsection{Usability design}

According to business executives, usability is the most important criterion for an ideal software agent. In the proposed agent design criteria, usability has four value added attributes which are personalisation, controllability, manageability, and ease of use. The relevant areas discussed in the conventional executive information system studies of usability design are limited mainly to the ease of use and value added presentation of data via user-friendly interface such as graphical, tabular, or textual information presentation (Young \& Watson, 1995; Watson et al., 1997). The usability criteria proposed here has extended the features of conventional usability design focusing in the ease of use to personalisation, controllability and manageability.

Personalisation - According to business executives, the first and primary value-added attribute in usability design is the personalisation. Riecken (2000), identifies that personalisation is motivated by the recognition of user's needs, and aims to meet those needs which are likely to result in a satisfying relationship with the user. Blaylock and Rees (1984) and Watkins (1984) argued that decision makers with different cognitive styles prefer different sets of information. The value and usefulness of information cannot be evaluated effectively without considering who uses that information. The findings suggest that personalisation allows executives to manage and customise information for specific purposes based on their individual domains, roles and preferences.

Controllability - The controllability attribute allows executive to exert control over the agent's behaviour and actions if they wish. Subsequent to the introduction of management information systems (MIS), Ackoff (1967) pointed out that an MIS should not be implemented unless the managers for whom it is intended are trained to evaluate and thus control the MIS rather than be controlled by it. One of Scapin and Bastien's (1997) ergonomic criteria for designing human-computer interfaces, explicit control, concerns both the system processing of explicit user actions and the control that users have on the processing of their actions by the system. Jones and McLeod (1986) demonstrated that executives can manage information to some extent by controlling the choice of information sources and media. Our findings suggest that executives want to have 
control over their information profiles, such as sources, types and contents. The findings also imply that executives must be able to make changes on their control criteria because their information requirements change over time and change with different issues.

Manageability - The manageability attribute is the ability to minimise information density to a digestible, manageable and appropriate amount at an appropriate interval. The over-abundance of distributed and heterogeneous information has created an environment in which executives are pressurised to spend more time to identify information of their interest. Ackoff (1967, p 148) argued that "Unless the information overload to which managers are subjected is reduced, any additional information made available by an MIS cannot be expected to be used effectively". Likewise, Scapin and Bastien (1997) argue that the less users are distracted by unnecessary information, the more they will be able to accomplish their task efficiently. It is essential to minimise the information density that concerns the users' workload from a perceptual and cognitive point of view with regard to the whole set of information presented to the users. Executives believed that manageability improves the decision making process because a small set of information is easier and quicker for them to digest and make sense of it, thus, increasing the overall quality of information.

Ease of use - According to Taylor (1986), ease of use has to do with system elements that are able to reduce difficulties in using the system. From the findings, executives raised the issues related to simplicity, accessibility and browsability. According to senior executives, simplicity could increase the use of the system with easy functionalities and user-friendly interface. Accessibility can reduce time and effort needed to gain access to information via simple or minimum steps to find answer from the system. Browsability can increase the efficiency of information process via "uncluttered" information presentation and organisation.

\subsection{Adaptability design}

Adaptability was identified as one of the most important success factor for DSS applications (Parker \& Sinclair, 2001). In Taylor's (1986) value-added model, adaptability is one of the user criteria that adds value in information systems. According to business executives, adaptability consists of four important attributes: coaching, contextual support, learning, and semantic support. Scapin and Bastien (1997) also consider adaptability as one of the ergonomic criteria of designing human-computer interfaces. An agent-based support system should be able to adapt to the environment in which the executive works. Therefore, the coaching and learning attribute would aim to respond to the concern with how information is needed and why. The contextual support and semantic support attributes would aim to respond to the concern of how well the system can respond to the uncertainty of executive information. 
Coaching - According to business executives, the most important attribute in adaptability design is coaching. The concept of coaching is similar to the explicit relevance feedback approach in the study of information retrieval (Salton \& Buckley, 1990). User's explicit relevance feedback is used to reformulate queries and also to create and refine user profiles (Korfhage, 1997; Quiroga \& Mostafa, 2002; Yang \& Chung, 2004; Singh \& Dey, 2005). The coaching attribute enables executives to train the system by giving explicit feedback in order to increase its robustness. This is achieved by gradually building an individual user's profile. The business executives stressed that the coaching process should be interactive, enabling the system to learn and thus improve the quality of information provided. Although there is a concern of increasing cognitive burden on users in the coaching process, the findings suggest that executives are willing to provide feedback to the system and don't see the coaching process as a burden if it helps the agent to build a more relevant user profile. To overcome the increasing cognitive workload, the coaching mechanism has to be "very simple and straightforward'. As executives become more confident in coaching the system, the process will become more manageable and less time consuming.

Learning - Learning can improve the adaptability through observing and monitoring user's information processing behaviour without requiring user's explicit feedback on retrieved information. This removes the cost, time and cognitive load needed as in explicit relevance feedback approach. The learning attribute refers to the capability of the system to improve its information processing activity by unobtrusively observing and monitoring executive's information processing behaviours and information preferences. The goal of learning is for system to adapt to the user's needs and interests independently. According to executives, the learning attribute is less significant and desirable than the coaching attribute. Executives seemed not to have developed trust to let agents learn their information processing behaviours, but they do recognise that self-learning by software agents will take time and can be improved gradually.

Contextual Support - The goal of contextual support is to reduce the ambiguity of information and increase its relevance according to the user's context. The concept of the contextual support attribute is taken from two approaches in the literature: one is the context-aware retrieval (CAR) approach, which retrieves contextaware information pertinent to the user's current physical location, device, application and organisational context (role, activity, shared process) (Brown \& Jones, 2001; Chanana et al., 2004; Kirsch-Pinheiro, 2005); and the other is the ambient computing intelligent environment (AmI) approach, which executes contextaware distributed tasks (Munoz et al., 2003; Murthy \& Krishnamurthy, 2005).

Semantic Support - One of the challenges of information processing is to transform distributed documentation into semantically enriched information. Semantic support occurs with the availability of relevant ontology. Relevant approaches to semantic support are text categorization, also know as text 
classification or topic spotting, the process of labelling and assigning natural language texts to predefined categories based on their content (Lewis \& Ringuette, 1994; Sebastiani, 2002). Machine learning techniques are widely used for automatically extracting semantic information in text categorization, as reviewed by Sebastiani (2002). According to executives, semantic support is important, but it is the least desirable attribute compared with coaching, learning and contextual support. Executives were aware of the need as well as the challenges of semantic support.

\subsection{Autonomy design}

Being autonomous is one of the distinctive features of an intelligent agent (Wooldridge \& Jennings, 1995; Hector \& Narasimhan, 2005). Wooldridge and Jennings (1995) define autonomy as the capability of agents to "operate without the direct intervention of humans or others, and have some kind of control over their actions and internal state" (p. 116). The autonomy of an agent requires not only autonomous execution, but also autonomous goals (Liu, 1998). From the findings, executives perceived the usefulness of an autonomy function as a way to reduce their information workload, hence, enabling them to focus on their interpersonal and decisional roles. Analysis of executives' comments suggests two important value added attributes to autonomy: spontaneity and proactivity.

Spontaneity - The "spontaneous" attribute is the capability of agents to perceive their environment and respond it spontaneously and autonomously (Wooldridge \& Jennings, 1995; Khedr \& Karmouch, 2005). An agent should be able to dynamically choose which actions to invoke and in what sequences, in response to the state of its environment (Liu, 1998). The vision of people amalgamated with their surroundings in a spontaneous way created a new, context-aware era of human-computer interaction. Agent systems should be able to understand the current situation and act on that understanding (Khedr \& Karmouch, 2005). Findings from the executive discussions and interviews revealed that the spontaneity attribute was perceived more desirable than proactivtiy.

Proactivity - Proactivity is the capability of agents to anticipate the environmental changes and exhibit goaldirected behaviour by taking the initiative where appropriate (Wooldridge \& Jennings, 1995). The agent does not need explicit instructions from the user, but goals that are set forth in the design or given to the agent at run time. With these goals set, the agent is responsible for deciding how and when to exhibit goal-directed process for the user (Liu, 1998). From the findings, executives perceived proactivity as a way to enhance indirect manipulation of information and thus to improve user's awareness of potentially useful information. This indirect manipulation does not require users to initiate all tasks explicitly and to monitor all events (Maes, 1994). For example, information is proactively manipulated to provide prompts, suggestions and 
recommendations to users via the user interfaces, and query is proactively expanded to reduce the mismatch of information.

\section{Conclusions and Implications}

It is argued that an adequate understanding of users' perceptions and requirements for intelligent agent based support and the associated system design and development provides a sound basis for advancing the development and application of agent-based systems. Therefore, this research has examined executives views concerning the design of ideal software agents to support their intelligence activities as defined by Simon's (1977) decision making theory. This study has established and empirically validated a set of design criteria for ideal intelligent agents. The design criteria emerged through an inductive approach based on extensive qualitative data generated from a preliminary study using three focus groups and further validated with a follow-up study using semi-structured interviews with 25 business executives. The informants, i.e. business executives in this context, expressed their views with in-depth explanations based on their experience regarding the nature of decision making in their fields of practice. They discussed and defined what are their ideal agent based support systems in a rich, convincing and well argued manner. Underpinning by the key concepts from the agent development literature, the design criteria derived from the executives' point of view are further categorised as system's usability, adaptability and autonomy. It is evident that the underlining capability to meet these criteria lies on the level of system intelligence.

This research has made a number of important contributions, which include:

- Generation of most desirable agent system design criteria based on usability-adaptability-autonomy (see figure 2) from the business executives' perspective using qualitative research methods in the data collection.

- Better understanding of user requirements based on the rich qualitative data generated through focus groups and interviews, thus providing a sound base for advancing the development and applications of agent based support systems.

- Important implications for advancing agent support systems in both research and practice. The empirically validated design criteria demonstrates the hierarchical level of systems intelligence required in supporting decision making and the order of the desirability from executives point of views. It shows that usability is the fundamental and most desirable criteria, followed by adaptability. Autonomy requires highest level of system intelligence, but is the least desirable functionality. The criteria can also serve as an evaluation tool in agent system design.

- Valuable insights into the nature of decision making, challenges and problems that executives are currently facing in their decision making process 
- Contribution to the current debate on the emerging challenges in decision making, the limitations of intelligent system to meet users' requirements, as well as the necessity, feasibility and user acceptance of replacing human intuition with intelligent agents.

Findings from the research have a number of important implications. They reveal that users' conservative attitudes towards using intelligent systems to replace intuitive judgment have remained unchanged over decades despite advances in technology development. Usability, as the most basic design criterion, remains as the most desirable feature of the ideal software agent and autonomy, as the most challenging feature of an agent, is considered as least desirable. The implication for agent system developers is that the simple, workable and trustworthy personalised software agents are what business executives want. Instead of focusing on research efforts in developing very sophisticated agent based support systems in the laboratory, IS researchers should respond to the users' requirements and develop the systems to meet the desires of users. In addition, personalisation remains the top requirement for agent support systems. Therefore, agent-based support systems must be able to adapt to individual's decision making environment and be personalised to their unique needs and specific context. The fears that executive expressed on the loss of control over the agent working for them require agent designers to incorporate appreciate control features to meet executives desire for controllability.

There are many challenges in developing and using an ideal agent-based system. From a technological perspective, despite optimistic expectations since the 1990s, the current technological development of software agent systems for decision support still remains at the stage of prototyping, conceptual or experimental systems. The technical challenges related to supporting executive intelligence activities are the software agents' capability to understand an executive as an individual user with specific domain of work and information, and to fit the intelligence activities into the right content and context. Technological advances in artificial intelligence appear to have made slow progress over the last two decades. There are still technological challenges in furthering AI techniques and alleviating the limitations and bottlenecks of intelligent systems in terms of representing human intuition and judgement.

The future application of software agents in supporting executive intelligence activities could potentially change executives' behaviour. This is a two-way interaction between the executives and software agents. It can be envisaged that an executive's intelligence role will not be weakened or replaced by software agents, because the agent is coached by the executive and is a part of the executive's decision making process. On the other hand, executives do not appear to have full confidence in trusting software agents and fear that software agents could take over some of their intelligence roles and limit their intellectual development, thus resulting in resistance to substantial reliance on software agents. 
The implementation of the empirically validated "usability-adaptability-autonomy" design in an agent-based system has implications to systems designers, as it sets up criteria for future attempts to develop intelligent agent systems that support executives' work. The realisation of the system relies on many factors including technology advances, organizational conditions, management support and executives' participation. The proposed design criteria attempt to reduce the information overload and equip executives with personalised assistance for continuous, self-reactive and self-adaptive approaches to acquiring, synthesizing and interpreting information for business intelligence with a view to determining a course of action. As a result, it has potential to enhance the firm's capability to know itself, its enemies and its business environment and enable executives to improve quality of insights in decision making that will lead to strategic advantage.

\section{References}

Ackoff, R. L. (1967) Management Misinformation Systems. Management Science, 14, B147-B156. Arnott, D. \& G. Pervan (2005) A critical analysis of decision support systems research. Journal of Information Technology, 20, 67-87.

Auster, E. \& C. W. Choo (1994) How senior managers acquire and use information in environmental scanning. Information Processing and Management, 30, 607-618.

Avison, D., G. Fitzgerald \& P. Powell (2001) Reflections on information systems practice, education and research: 10 years of the Information Systems Journal. Information Systems Journal, 11, 3-22.

Belfourd, T. \& J. Furner (1997) Fast learners or time wasters? Intelligent agents on the Web: a user study. Managing Information, 4, 32-34.

Benbasat, I. \& R. W. Zmud (1999) Empirical research in information systems: The practice of relevance. Mis Quarterly, 23, 3-16.

Bevan, N. \& M. Azuma (1997) Quality in use: incorporating human factors into the software engineering lifecycle. Software Engineering Standards Symposium and Forum, 1997. 'Emerging International Standards'. ISESS 97., Third IEEE International, 169-179.

Bevan, N. \& M. Macleod (1994) Usability Measurement in Context. Behaviour \& Information Technology, $13,132-145$.

Blaylock, B. K. \& L. P. Rees (1984) Cognitive-Style and the Usefulness of Information. Decision Sciences, $15,74-91$.

Brown, P. J. \& G. J. F. Jones. 2001. Context-aware Retrieval: Exploring a New Environment for Information Retrieval and Information Filtering. 253-263.

Buchenau, M. \& J. F. Suri. 2000. Experience prototyping. In Proceedings of the conference on Designing interactive systems: processes, practices, methods, and techniques, 424-433. New York City: ACM Press.

Chanana, V., A. Ginige \& S. Murugesan. 2004. Improving information retrieval effectiveness by assigning context to documents. In Proceedings of the 2004 international symposium on Information and communication technologies, 86-91. Nevada.

Edmunds, A. \& A. Morris (2000) The problem of information overload in business organisations: a review of the literature. International Journal of Information Management, 20, 17-28.

Eppler, M. J. \& J. Mengis (2004) The concept of information overload: A review of literature from organization science, accounting, marketing, MIS, and related disciplines. Information Society, 20, 325-344.

Gao, S. \& D. Xu (2009) Conceptual modeling and development of an intelligent agent-assisted decision support system for anti-money laundering. Expert Systems with Applications, 36, 1493-1504. 
Hector, A. \& V. L. Narasimhan (2005) A new classification scheme for software agents. Proceedings of the Third International Conference on Information Technology and Applications, 1, 191-196.

Hevner, A. R., S. T. March, K. Park \& S. Ram (2004) Design Science in Information Systems Research. MIS Quarterly, 28, 75-105.

Iivari, J., H. Isomäki \& S. Pekkola (2010) The user - the great unknown of systems development: reasons, forms, challenges, experiences and intellectual contributions of user involvement. Information Systems Journal, 20, 109-117.

Jennings, N. R., K. Sycara \& M. Wooldridge (1998) A Roadmap of Agent Research and Development. Autonomous Agents and Multi-Agent Systems, 1, 7-38.

Jones, J. W. \& R. Mcleod (1986) The Structure of Executive Information-Systems - an Exploratory Analysis. Decision Sciences, 17, 220-249.

Kaasinen, E. (1999) Usability challenges in agent based services. Intelligence in Services and Networks, 1597, 131-142.

Khedr, M. \& A. Karmouch (2005) ACAI: agent-based context-aware infrastructure for spontaneous applications. Journal of Network and Computer Applications, 28, 19-44.

Kirsch-Pinheiro, M. 2005. Context-aware filtering for collaborative web systems: adapting the awareness information to the user's context. In Proceedings of the 2005 ACM symposium on Applied computing, 1668-1673. New Mexico.

Kling, R. (2007) What is social informatics and why does it matter? (Reprinted from D-Lib Magazine, January 1999). Information Society, 23, 205-220.

Korfhage, R. R. 1997. Information storage and retrieval. New York: Wiley.

Kumar, A. \& P. Palvia (2001) Key data management issues in a global executive information system. Industrial Management \& Data Systems, 101, 153-164.

Lab, T. I. S. 2009. Multi-Agent Systems. The Robotics Institute - Carnegie Mellon University.

Lacity, M. C. \& M. A. Janson (1994) Understanding Qualitative Data: A Framework of Text Analysis Methods. Journal of Management Information Systems, 11, 137-156.

Lee, C. K. M., H. C. W. Lau, G. T. S. Ho \& W. Ho (2009) Design and development of agent-based procurement system to enhance business intelligence. Expert Systems with Applications, 36, 877-884.

Lewis, D. D. \& M. Ringuette. 1994. A Comparison of Two Learning Algorithms for Text Categorization. In Proceedings of the Third Annual Symposium on Document Analysis and Information Retrieval, 81-93.

Liu, S. H. (1998) Strategic scanning and interpretation revisiting: foundations for a software agent support system - Part 2: scanning the business environment with software agents. Industrial Management \& Data Systems, 98, 362-+.

Lynch, T. and S. Gregor (2004) " User Participation in Decision Support Systems Development:

Influencing System Outcomes," European Journal of Information Systems (13) 4, pp. 286 -

301.

Mackrell, D., D. Kerr \& L. von Hellens (2009) A qualitative case study of the adoption and use of an agricultural decision support system in the Australian cotton industry: The socio-technical view. Decision Support Systems, 47, 143-153.

Maes, P. (1994) Agents That Reduce Work and Information Overload. Communications of the Acm, 37, 3140.

Mason, J. 2002. Qualitative researching. Lomdom: Sage.

Morse, J. M. (1997) "Perfectly healthy, but dead": The myth of inter-rater reliability. Qualitative Health Research, 7, 445-447.

Mumford, E. (2006) The story of socio-technical design: reflections on its successes, failures and potential. Information Systems Journal, 16, 317-342.

Munoz, M. A., M. Rodriguez, J. Favela, A. I. Martinez-Garcia \& V. M. Gonzalez (2003) Context-aware mobile communication in hospitals. Computer, 36, 38-+.

Murthy, V. K. \& E. V. Krishnamurthy. 2005. Contextual information management using contract: based workflow. In Proceedings of the 2nd Conference on Computing Frontiers, 236-245.

Myers, M. D. (1997) Qualitative research in information systems. Mis Quarterly, 21, 241-242.

Nicolson, P. \& P. Anderson (2003) Quality of life, distress and self-esteem: A focus group study of people with chronic bronchitis. British Journal of Health Psychology, 8, 251-270. 
Nwana, H. S. (1996) Software agents: An overview. Knowledge Engineering Review, 11, 205-244.

Nwana, H. S. \& D. T. Ndumu (1999) A perspective on software agents research. Knowledge Engineering Review, 14, 125-142.

Parker, C. \& M. Sinclair (2001) User-centred design does make a difference. The case of decision support systems in crop production. Behaviour \& Information Technology, 20, 449-460.

Quiroga, L. M. \& J. Mostafa (2002) An experiment in building profiles in information filtering: the role of context of user relevance feedback. Information Processing \& Management, 38, 671-694.

Riecken, D. (2000) Personalized views of personalization. Communications of the Acm, 43, 27-28.

Salton, G. \& C. Buckley (1990) Improving Retrieval Performance by Relevance Feedback. Journal of the American Society for Information Science, 41, 288-297.

Scapin, D. L. \& J. M. C. Bastien (1997) Ergonomic criteria for evaluating the ergonomic quality of interactive systems. Behaviour \& Information Technology, 16, 220-231.

Sebastiani, F. (2002) Machine learning in automated text categorization. Acm Computing Surveys, 34, 1-47.

Shapira, B., P. Shoval \& U. Hanani (1999) Experimentation with an information filtering system that combines cognitive and sociological filtering integrated with user stereotypes. Decision Support Systems, 27, 5-24.

Shaw, N. G., A. Mian \& S. B. Yadav (2002) A comprehensive agent-based architecture for intelligent information retrieval in a distributed heterogeneous environment. Decision Support Systems, 32, 401415.

Silver, M. S., M. L. Markus \& C. M. Beath (1995) The Information Technology Interaction-Model - a Foundation for the Mba Core Course. Mis Quarterly, 19, 361-390.

Simon, H. A. 1977. The new science of management decision. NJ: Prentice-Hall.

Singh, S. \& L. Dey (2005) A rough-fuzzy document grading system for customized text information retrieval. Information Processing \& Management, 41, 195-216.

Taylor, R. S. 1986. Value-added processes in information systems. New Jersey: Ablex Publishing.

Teresa, T. L. L. \& S. G. G. Shirley (2004) User participation in decision support systems development: Influencing system outcomes. European Journal of Information Systems: An Official Journal of the Operational Research Society, 13, 286-301.

Turban, E. \& J. E. Aronson 1998. Decision Support Systems and Intelligent Systems. London: Prentice-Hall International Inc.

Watkins, P. R. (1984) Preference Mapping of Perceived Information-Structure - Implications for Decision Support Systems-Design. Decision Sciences, 15, 92-106.

Watson, H. J., G. Houdeshel \& R. K. Rainer Jr 1997. Building Executive Information Systems and other Decision Support Applications. Canada: John Wiley \& Sons.

Wecel, K. 2007. EU research project: ENIRAF - Enhanced Information Retrieval and Filtering for Analytical Systems.

Wooldridge, M. \& N. R. Jennings (1995) Intelligent Agents - Theory and Practice. Knowledge Engineering Review, 10, 115-152.

Yang, C. C. \& A. Chung (2004) Intelligent infomediary for web financial information. Decision Support Systems, 38, 65-80.

Young, D. \& H. J. Watson (1995) Determinates of Eis Acceptance. Information \& Management, 29, 153-164. 
Table 1. Participants profile of focus groups

\begin{tabular}{|c|c|c|c|c|c|c|c|c|}
\hline \multirow{2}{*}{$\begin{array}{l}\text { Focus } \\
\text { Group } \\
\text { (FG) }\end{array}$} & \multirow{2}{*}{$\begin{array}{l}\text { number of } \\
\text { participant } \\
\mathrm{s}\end{array}$} & \multicolumn{3}{|c|}{ Management Level } & \multicolumn{4}{|c|}{ Organisation's Market } \\
\hline & & $\begin{array}{l}\text { Strateg } \\
\text { ic }\end{array}$ & Tactical & Operational & Regiona & National & $\begin{array}{l}\text { Europea } \\
n\end{array}$ & Global \\
\hline 1 & 7 & 4 & 2 & 1 & 2 & - & - & 5 \\
\hline 2 & 8 & 6 & - & 2 & 2 & 2 & - & 4 \\
\hline 3 & 16 & 5 & 10 & 1 & 4 & 5 & 1 & 6 \\
\hline Total & 31 & 15 & 12 & 4 & 8 & 7 & 1 & 15 \\
\hline$\%$ & & $48 \%$ & $39 \%$ & $13 \%$ & $25 \%$ & $24 \%$ & $3 \%$ & $48 \%$ \\
\hline
\end{tabular}

Table 2. Participants profile in interviews

\begin{tabular}{|l|l|l|l|}
\hline No & $\begin{array}{l}\text { Participant } \\
\text { (pseudo name) }\end{array}$ & Position & $\begin{array}{l}\text { Company Size } \\
\text { by employees) }\end{array}$ \\
\hline 1 & Adam & Deputy Managing Director & 250 \\
\hline 2 & Becky & Head of Corporate Governance & 12000 \\
\hline 3 & Chris & Director & 100 \\
\hline 4 & David & Managing Director & 400 \\
\hline 5 & Eve & Chief Operating Officer & $130($ UK) \\
\hline 6 & Ford & Service Director & - \\
\hline 7 & Gary & Chief Information Officer & - \\
\hline 8 & Henry & Associate Director & - \\
\hline 9 & lan & Strategic Planning Manager & 150 \\
\hline 10 & John & Managing Director & 420 \\
\hline 11 & Ken & Deputy Director & 100 \\
\hline 12 & Larry & Head of CEO & 1200 \\
\hline 13 & Mark & Trading Director & 400 \\
\hline 14 & Nelson & Customer Centre Manager & 150 \\
\hline 15 & Oscar & Chief Executive Officer & 2600 \\
\hline 16 & Peter & Chief Operating Officer & 1000 \\
\hline 17 & Quin & Business Development Director & 76 \\
\hline 18 & Robert & Vice President & 1900 \\
\hline 19 & Smith & Chief Finance Officer & \\
\hline 20 & Tim & Middle Manager & 150 \\
\hline 21 & Victor & General Manager of Group & 300 \\
\hline 22 & William & Operations \& Systems Director & 1500 \\
\hline 23 & Xandra & Head of IT Strategy & 30000 \\
\hline 24 & Yann & Director & 200 \\
\hline 25 & Zach & External Relations Director & 4000 \\
\hline & & & \\
\hline
\end{tabular}


Table 3. Thematic analysis of focus group data with sample supporting evidence (direct quotation)

\begin{tabular}{|c|c|c|}
\hline Raw Data & $1^{\text {st }}$ order theme & $\begin{array}{l}2^{\text {nd }} \\
\text { theme }\end{array}$ \\
\hline $\begin{array}{l}\text { "I think that should be simple for recipient to utilise the information." } \\
\text { "... what I can see is minimum management." } \\
\text { a complex form." }\end{array}$ & ease of use & \\
\hline $\begin{array}{l}\text { "...must be tailored made to individual industries, according to the } \\
\text { information needs." } \\
\text { "...provide personal feature of information rather than a generic one." } \\
\text { "...how you want to search, how you use it and it almost needs to be } \\
\text { tailored into the context of the organisation." }\end{array}$ & personalisation & - Usability \\
\hline $\begin{array}{l}\text { "...you need control over how you, what you want to see, what you } \\
\text { don't want to see." } \\
\text { "...is to define what he wants and how much control of information he } \\
\text { will get." }\end{array}$ & controllability & \\
\hline $\begin{array}{l}\text { "...you still got to teach the agent what you need." } \\
\text { "I think the fact we need to re-teach, reteach and reteach." } \\
\text { others." }\end{array}$ & $\begin{array}{l}\text { coaching (user } \\
\text { feedback) }\end{array}$ & \multirow{4}{*}{ Adaptability } \\
\hline $\begin{array}{l}\text { "...in terms of the profile of the agent, presumably it can retain some of } \\
\text { your interests and thoughts of yesterday as well as today." } \\
\text { "...I think the fact is that the system would have learning curve." }\end{array}$ & $\left\{\begin{array}{l}\text { learning from } \\
\text { user profile }\end{array}\right.$ & \\
\hline $\begin{array}{l}\text { "...need to be knowledge-based in order to process and understand the } \\
\text { level of important." } \\
\text { "It depends on whether they will actually tell you the context, } \\
\text { justification of where about the information are coming from..." }\end{array}$ & $\begin{array}{l}\text { contextual } \\
\text { support }\end{array}$ & \\
\hline $\begin{array}{l}\text { "...the way to improve is to understand the natural language." } \\
\text { "There's also the complexity of language ... there might be in my head } \\
\text { ten oleven different words which mean the same thing." }\end{array}$ & $\begin{array}{l}\text { semantic } \\
\text { suppport }\end{array}$ & \\
\hline $\begin{array}{l}\text { "...keep you updated with information from external business } \\
\text { environment that is spontaneous." } \\
\text { ".... when I come in the morning, there will be something to look at ..." } \\
\text { "...you set them right and run them in the background..." } \\
\text { change." }\end{array}$ & spontaneity & \multirow[t]{2}{*}{ Autonomy } \\
\hline $\begin{array}{l}\text { "...set themselves up with a piece of information that leads you } \\
\text { somewhere else." } \\
\text { "I mean as information is changing, it would pick it up and bring it to } \\
\text { you." } \\
\text { "If the agent hasn't searched for a while, it could actually suggest to the } \\
\text { user." }\end{array}$ & proactivity & \\
\hline
\end{tabular}


Table 4. A summary of interview data analysis

\begin{tabular}{|l|l|l|l|l|}
\hline Criteria & $\begin{array}{c}\text { Total } \\
\text { Percentage }\end{array}$ & Attribute & $\begin{array}{l}\text { Percentage } \\
\text { in sub-group }\end{array}$ & $\begin{array}{l}\text { Total } \\
\text { percentage }\end{array}$ \\
\hline Usability & $92 \%(23 / 25)$ & Personalisation & $74 \%(17 / 23)$ & $68 \%(19 / 25)$ \\
\hline & & Controllability & $65 \%(15 / 23)$ & $60 \%(15 / 25)$ \\
\hline & $\begin{array}{l}\text { Manageability } \text { (new } \\
\text { attribute) }\end{array}$ & $43 \%(10 / 23)$ & $40 \%(10 / 25)$ \\
\hline $\begin{array}{l}\text { Adaptabilit } \\
\text { y }\end{array}$ & $84 \%(21 / 25)$ & Ease of use & $39 \%(9 / 23)$ & $36 \%(9 / 25)$ \\
\hline & & Coaching & $57 \%(12 / 21)$ & $48 \%(12 / 25)$ \\
\hline & & Learning & $52 \%(11 / 21)$ & $44 \%(11 / 25)$ \\
\hline & & Semantic Support & $33 \%(7 / 21)$ & $28 \%(7 / 25)$ \\
\hline Autonomy & $64 \%(16 / 25)$ & Spontaneity & $75 \%(12 / 16)$ & $48 \%(12 / 25)$ \\
\hline & & Proactivity & $44 \%(7 / 16)$ & $28 \%(7 / 25)$ \\
\hline
\end{tabular}




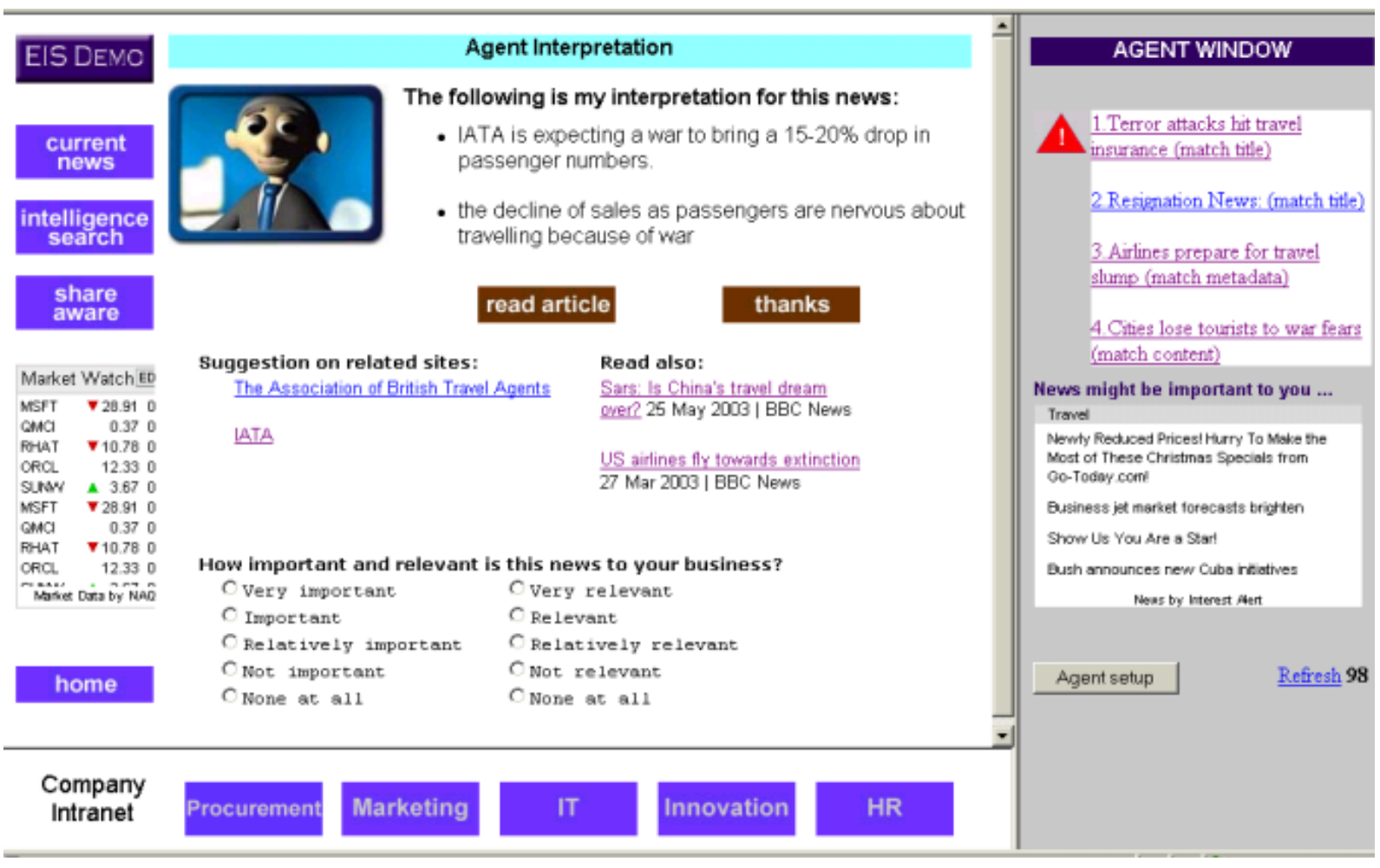

Figure 1. A sample user interface of agent supported interpretation and learning 


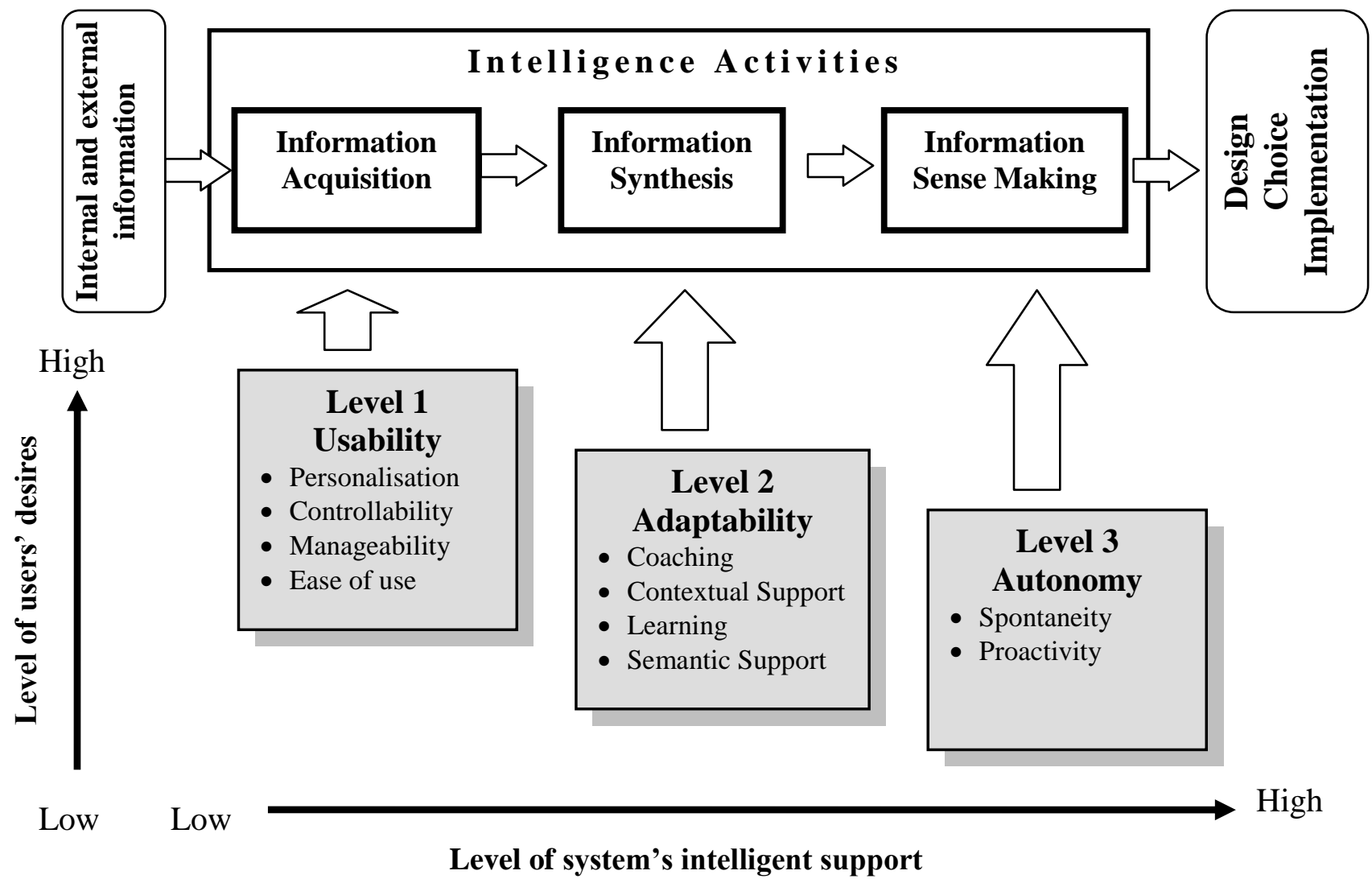

Figure 2. Executives design criteria for ideal software agents 


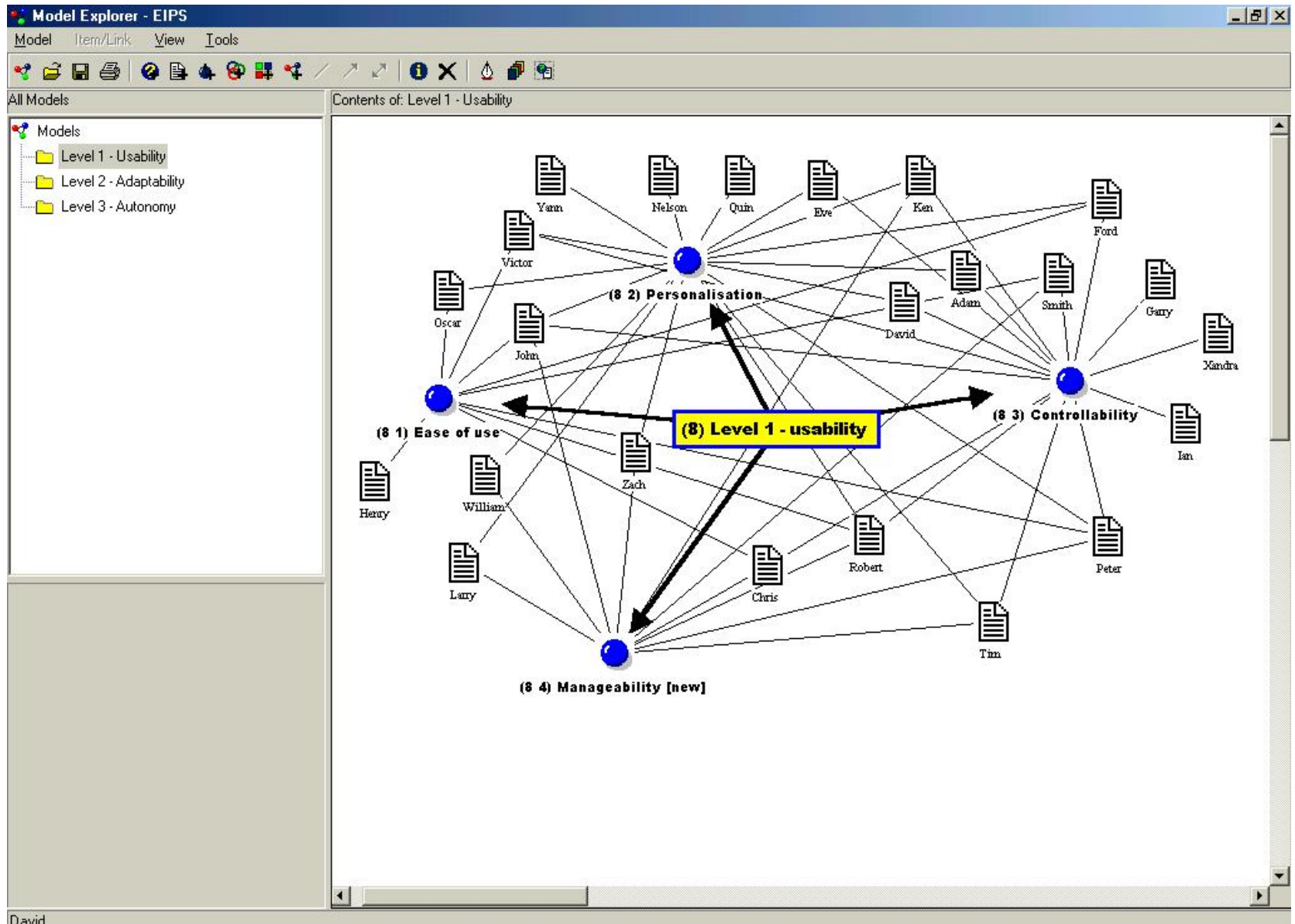

Figure 3. An example of data analysis in confirming usability criteria using Nvivo 